
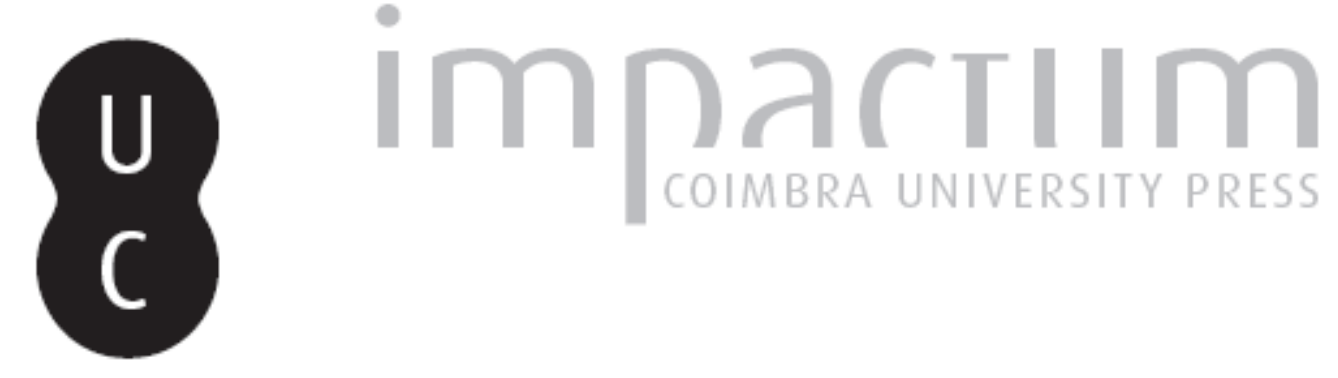

\title{
Ensaio metodológico para a categorização territorial do município de Lisboa utilizando dados dos censos de 2011
}

Autor(es): $\quad$ Pereira, Margarida; Nogueira, Helena

Publicado por: Imprensa da Universidade de Coimbra

URL

persistente:

URI:http://hdl.handle.net/10316.2/43406

DOI:

DOI:https://doi.org/10.14195/0871-1623_36_2

Accessed : $\quad$ 26-Apr-2023 15:25:01

A navegação consulta e descarregamento dos títulos inseridos nas Bibliotecas Digitais UC Digitalis, UC Pombalina e UC Impactum, pressupõem a aceitação plena e sem reservas dos Termos e Condições de Uso destas Bibliotecas Digitais, disponíveis em https://digitalis.uc.pt/pt-pt/termos.

Conforme exposto nos referidos Termos e Condições de Uso, o descarregamento de títulos de acesso restrito requer uma licença válida de autorização devendo o utilizador aceder ao(s) documento(s) a partir de um endereço de IP da instituição detentora da supramencionada licença.

Ao utilizador é apenas permitido o descarregamento para uso pessoal, pelo que o emprego do(s) título(s) descarregado(s) para outro fim, designadamente comercial, carece de autorização do respetivo autor ou editor da obra.

Na medida em que todas as obras da UC Digitalis se encontram protegidas pelo Código do Direito de Autor e Direitos Conexos e demais legislação aplicável, toda a cópia, parcial ou total, deste documento, nos casos em que é legalmente admitida, deverá conter ou fazer-se acompanhar por este aviso.

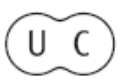




\section{Cadernos de Ceografia}

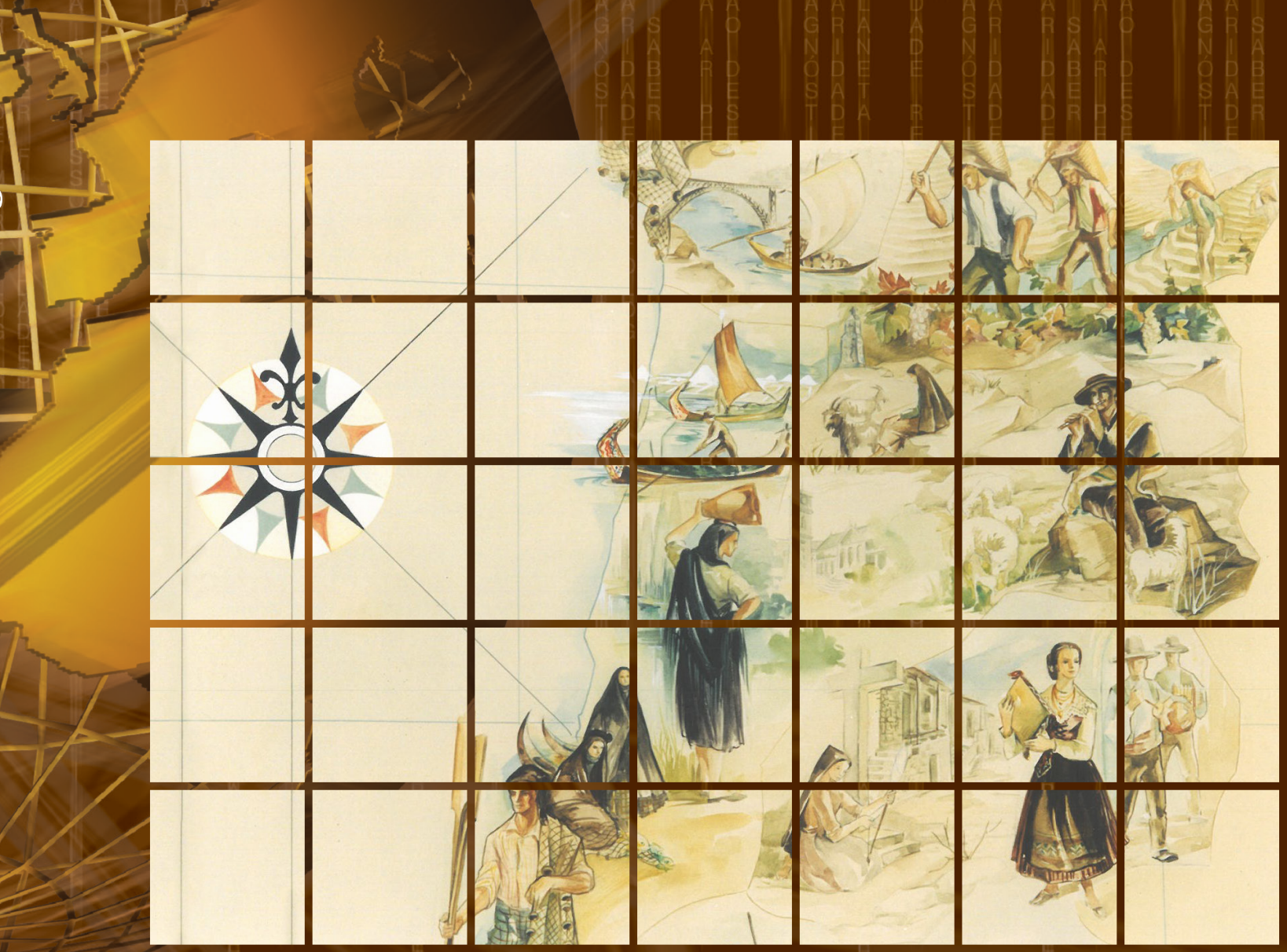

Imprensa da Universidade de Coimbra Faculdade de Letras | Universidade de Coimbra 


\section{Ensaio metodológico para a categorização territorial do município de Lisboa utilizando dados dos censos de 2011 Methodological test for the territorial categorization of the municipality of Lisbon using data from the 2011 census}

\section{Margarida Pereira}

Centro de Investigação em Antropologia e Saúde da Universidade de Coimbra

mmiguel06@gmail.com

ORCID: 0000-0001-5980-604X

\section{Helena Nogueira}

Departamento de Geografia e Turismo, Centro delnvestigação em Antropologia e Saúde, Universidade de Coimbra helenamarquesnogueira@gmail.com

ORCID: 0000-0001-5724-3538

\section{Sumário:}

A visão mais tradicional em Geografia perspetiva o território como uma realidade dicotómica onde se cruzam características sociodemográficas e biofísicas, afirmando a literatura a respeito, que ambas as dimensões territoriais coexistem e interagem. No entanto, o número de indicadores de cada dimensão é vasto e torna complexa a categorização do território - tarefa que gera conhecimento sobre as diferenças entre territórios e auxilia um melhor planeamento, mais direcionado e estratégico. 0 objetivo deste trabalho é categorizar a área do Município de Lisboa, ao nível da secção estatística, integrando informação sobre os aspetos físicos e sociais. Para tal utilizaram-se técnicas de análise estatística multivariada e complementares: Análise em Componentes Principais (aplicada aos aspetos físicos e sociais do território) e Classificação Hierárquica Ascendente (baseada nos fatores previamente extraídos na Análise em Componentes Principais). Os clusters resultantes foram mapeados e a sua autocorrelação espacial foi testada.

Palavras-Chave: Território; Análise Componentes Principais; Classificação Hierárquica Ascendente; I de Moran.

\section{Abstract:}

The more traditional perspective in Geography views territory as a dichotomous reality of sociodemographic and biophysical characteristics, with the specialty literature indicating, that both territorial dimensions coexist and interact. However, the number of indicators for each dimension is vast and makes the categorization of territory complex - a task that generates knowledge about the differences between territories, improving the planning process and making it more directed and strategic. This work main goal is to categorize Lisbon Municipality area at the statistical section level, integrating information on the physical and social aspects. For this purpose, multivariate and complementary statistical analysis techniques were used: Principal Component Analysis (applied to the physical and social aspects of the territory) and Hierarchical Classification Analysis (based in the factors extracted in the Principal Component Analysis). Clusters were mapped and its spatial autocorrelation was tested.

Keywords: Territory; Principal Components Analysis; Hierarchical Classification Analysis; Moran's I.

\section{Introdução}

O território pode ser definido como um espaço delimitado e preciso, com múltiplas dimensões, no qual várias relações de poder atuam (Albagli, 2004; Faria e Bortolozzi, 2009). Território é o resultado da integração da cultura no ambiente (Braga, 2007), contudo, não é só uma construção social resultante das relações de poder históricas, mas também um espaço natural (Haesbaert e Limonad, 2007).
A definição de território varia de acordo com diferentes ciências, o que torna este conceito ambíguo (Faria e Bortolozzi, 2009). Do ponto de vista político, o território está intimamente relacionado com as fronteiras do Estado/Nação já a perspetiva ambiental enfatiza as características biofísicas do território (Faria e Bortolozzi, 2009). Como o território integra diversas dimensões nomeadamente, geográficas, antropológicas, culturais, sociais, económicas e bioecológicas (Albagli, 2004), pode afirmar- 
-se que a escolha dos aspetos a enaltecer depende do objetivo do estudo e da conceção de território do próprio investigador (Faria e Bortolozzi, 2009).

Este estudo é baseado numa visão geográfica do território enquanto espaço produzido, resultante de um conjunto de processos nos quais os aspetos materiais, físicos e os aspetos sociais, resultantes da ação humana, são indissociáveis e interdependentes (Haesbaert e Limonad, 2007).

Albagli (2004: 27) afirma que: “As diferenças e desigualdades territoriais residem tanto em suas próprias características físicas e sociais, como na forma em que se inserem em estruturas mais amplas. Cada território é, portanto, moldado a partir da combinação de condições e forças internas e externas, devendo ser compreendido como parte de uma totalidade espacial."

Isto significa que cada unidade territorial é determinada por fatores endógenos e exógenos e ainda pela forma como estes interagem: importam as características intrínsecas, que conferem a cada território uma estrutura peculiar, mas esta determina a forma como cada território se insere em espaços mais alargados o que, por sua vez, condiciona a evolução da sua própria estrutura interna.

A categorização e diferenciação de cada unidade territorial de acordo com o seu nível de desenvolvimento, ou condições de vida que oferece, por exemplo, são uma tentativa dos investigadores compreenderem e explicarem as diferenças entre territórios (lanoș et al., 2013; Martín e Barros, 2015).
Além disso, analisar a forma como os territórios se relacionam entre si, observando as redes espaciais formadas de acordo com determinados aspetos, permite um planeamento estratégico e mais direcionado (Martín e Barros, 2015).

Por exemplo, estudos no âmbito da saúde pública usam frequentemente índices de privação ao nível da área, em vez de informação individual, por forma a identificar áreas de maior vulnerabilidade, logo menos saudáveis, que se constituem como áreas prioritárias no combate às desigualdades em saúde (Allik et al., 2016; Knighton et al., 2016). Estes índices, também designados como Índices de Privação Geográfica, usam geralmente dados dos censos e estão devidamente validados na Europa Ocidental (Knighton et al., 2016). Sendo a privação um conceito multidimensional os índices compósitos refletem melhor do que um só indicador, o verdadeiro nível de privação em diferentes escalas geográficas, como aliás a evidência existente a respeito sugere (Lian et al., 2016).

Como referido anteriormente, cada território é o produto da interação entre aspetos físicos e sociais, e ambas as dimensões do território podem ser operacionalizadas por um vasto número de indicadores. 0 objetivo deste estudo é categorizar a área do Município de Lisboa, ao nível da secção estatísti$\mathrm{ca}$, integrando simultaneamente informação sobre os aspetos físicos e sociais, e testar a existência de autocorrelação espacial.

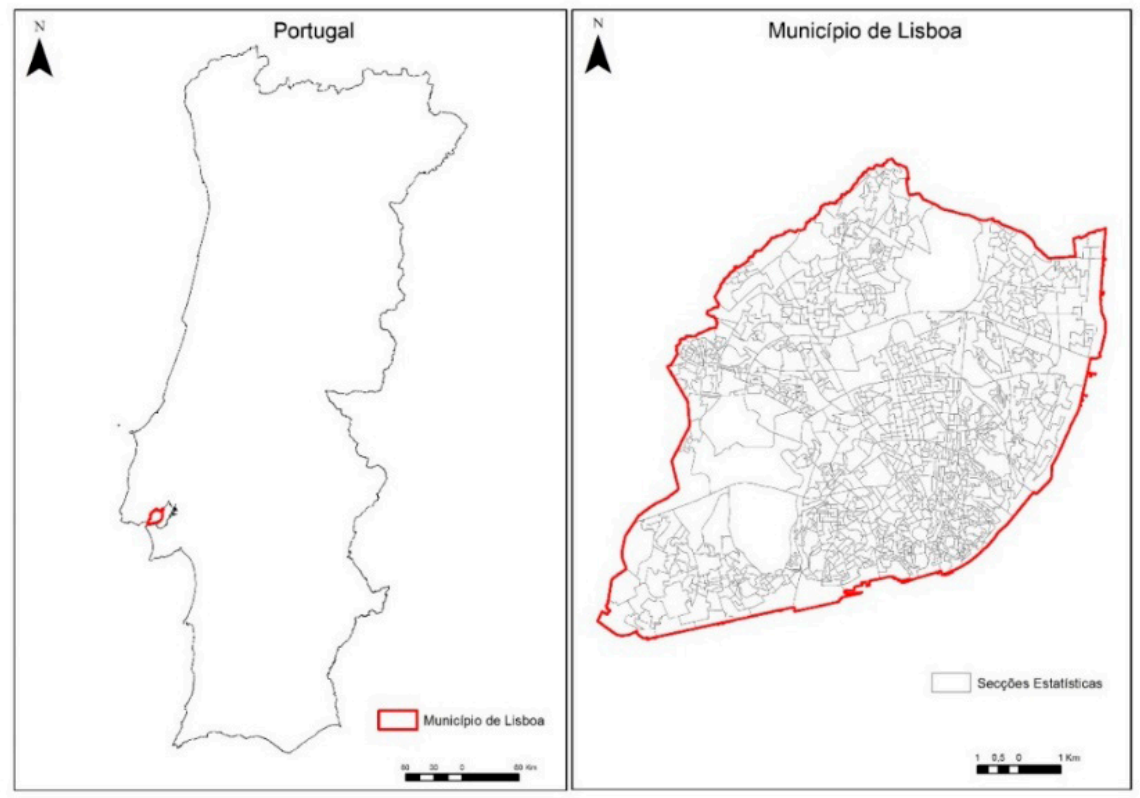

Figura 1

Área de estudo: município de Lisboa por secções estatísticas. 


\section{Métodos}

Este estudo foi realizado na área do Município de Lisboa, capital de Portugal, que é composta por 1054 secções $^{1}$. No entanto, as análises realizadas reportam-se a 1053 secções devido à falta de informação para uma secção.

\section{Recolha e Organização dos Dados}

Os dados utilizados neste estudo foram recoIhidos ao nível das secções estatísticas do Município de Lisboa. Do censo de 2011, disponível no website do Instituto Nacional de Estatística (INE), recolheram-se 61 variáveis sociodemográficas, económicas e sobre os edifícios; a informação do uso do solo (a nível 2) foi recolhida no website da Direção Geral do Território², perfazendo 11 variáveis, datadas de 2007.

Os dados foram agrupados em duas grandes dimensões: aspetos físicos (AF) que incluem informação sobre edifícios e uso do solo e, aspetos sociais (AS) integrando informação demográfica e socioeconómica. Depois, a informação foi convertida em percentagem resultando em 34 indicadores na dimensão $\mathrm{AF}$ e 24 indicadores na dimensão AS.

\section{Análise dos Dados}

Todas as análises estatísticas foram realizadas utilizando o SPSS na sua versão 22 exceto o I de Moran que foi calculado em ArcGIS (v.10.4.1).

Para reduzir o número de indicadores em cada uma das dimensões (AF e AS), o método estatístico utilizado foi a Análise Fatorial em Componentes Principais (ACP) (Messer et al., 2006; Vyas e Kumaranayake, 2006). A ACP é amplamente utilizada nos estudos de geografia urbana, mais especificamente na investigação focada em questões sociais (Langlois e Kitchen, 2001). A ACP foi realizada com uma rotação ortogonal Varimax, que facilita a interpretação das componentes pela maximização da variação intra e intercomponentes ${ }^{3}$, procurando deste modo que em cada componente apenas alguns indicadores apresentem valores de loadings ${ }^{4}$ elevados, surgindo nos restantes fatores com valores próximos de zero.

\footnotetext{
Secções Estatísticas - unidade territorial de aproximadamente 300 alojamentos.

2 http://www.dgterritorio.pt/cartografia_e_geodesia/cartografia/cartografia_tematica/carta_de_ocupacao_do_solo_cos_/cos_2007/

3 O conceito componente ou fator serão utilizados indistintamente.

4 Os loadings representam o coeficiente de correlação entre cada variável e o fator em questão e a sua interpretação baseia-se no valor absoluto.
}

A ACP do grupo AF resultou inicialmente em 12 fatores de acordo com o método de Kaiser (valor de eigenvalues ${ }^{5}$ acima de 1 ), o mais comumente utilizado (Langlois e Kitchen, 2001). Para reduzir o número de fatores, eliminou-se alguma da informação original, excluindo-se da análise os indicadores $^{6}$ que apresentavam valores de loadings entre $-0,49$ e 0,49 em todas as componentes inicialmente extraídas, o que resultou numa nova extração de 6 fatores. Não foram excluídos indicadores da ACP realizada na dimensão dos AS pois os resultados da primeira análise foram mais parcimoniosos: 5 fatores. Para além da consideração dos loadings, foram analisados e cartografados os scores ou coordenadas ${ }^{7}$ resultantes da ACP.

As ACP foram seguidas e complementadas por uma Classificação Hierárquica Ascendente (CHA), vulgarmente designada por análise de clusters, efetuada com a utilização simultânea dos 6 fatores da AF e os 5 fatores da AS e recorrendo ao método Ward e à distância euclidiana quadrática enquanto métodos de avaliação das similaridades e distâncias entre elementos e entre grupos de elementos. Este tipo de análise não parte de qualquer assunção prévia sobre os dados (Norusis, 2005).

O I de Moran mede a autocorrelação espacial através da análise do grau de dependência entre os valores das secções estimando quanto do valor de cada secção depende dos valores das secções vizinhas. $O$ índice de Moran testa as seguintes hipóteses: HO - não há dependência espacial; H1 - há dependência espacial. Apresenta-se de seguida a fórmula de cálculo deste índice.

$$
\begin{aligned}
& \boldsymbol{I}=\frac{\boldsymbol{n}}{\sum_{i=1}^{n} \sum_{j}^{n}=\mathbf{1} \boldsymbol{w i j}} \frac{\sum_{i=1}^{n} \boldsymbol{w i j}(\boldsymbol{y i}-\overline{\boldsymbol{y}})(\boldsymbol{y j}-\overline{\boldsymbol{y}})}{\sum_{i=1}^{n}(\boldsymbol{y} \boldsymbol{i}-\overline{\boldsymbol{y}})^{\mathbf{2}}} \\
& \text { W - matriz de vizinhança } \\
& \text { yi - média de cada secção } \\
& \bar{y} \text { - média } \\
& \text { yj - média dos vizinhos } \\
& \mathrm{n} \text { - número de secções } \\
& \text { Fórmula } 1 \text { Índice de Moran Global }
\end{aligned}
$$

\footnotetext{
O eigenvalue, ou valor próprio, representa a variância extraída pelo fator.

6 Indicadores excluídos: \% edifícios exclusivamente residenciais, \% edifícios principalmente residenciais, \% edifícios construídos até 1991, \% edifícios construídos até 2011 , \% alojamentos familiares, \% alojamentos com $200 \mathrm{~m}^{2}$, \% alojamentos com parqueamento, \% Indústria/Comércio/ Transporte, \% Resíduos, \% Espaços Verdes, de Lazer e Culturais, \% Culturas Permanentes, \% Agricultura Heterogénea, \% Floresta, \% Floresta Arbórea, \% Vegetação escassa e \% Água Interior.

7 As coordenadas, ou "scores" representam o valor da projeção ortogonal de um determinado individuo (neste caso, de uma secção) sobre um determinado fator. A análise das coordenadas coloca em evidência as semelhanças ou contrastes entre grupos de indivíduos face às combinações de variáveis definidas por cada fator (Nogueira, 2006).
} 
Este índice varia entre -1 e 1; quanto mais próximo estiver de 1 mais forte será a autocorrelação espacial, quanto mais se aproximar de -1 , menos semelhantes entre si são as áreas vizinhas. Quando o valor é igual ou próximo de zero significa que não existe autocorrelação espacial, ou seja, as áreas em estudo são espacialmente independentes. Para calcular a significância estatística do I de Moran, utiliza-se o teste de pseudossignificância.

O I de Moran foi calculado sobre o resultado da CHA, previamente calculado em SPSS e importado para ambiente ArcMap, e escolhendo como conceptualização das relações espaciais a contiguidade de limites e cantos, ou seja tendo em conta os valores de todas as secções que partilham uma fronteira, um nódulo ou que se sobrepõem.

\section{Resultados}

\section{Análise em Componentes Principais Aspetos Físicos}

No Quadro I pode observar-se o valor dos loadings mais elevados por fator e a respetiva percentagem de variância explicada. Os seis fatores resultantes explicam quase $75 \%$ da variância deste grupo de indicadores.

0 primeiro fator está relacionado com as condições da habitação, como a percentagem de alojamentos com água, retrete e esgoto. As variáveis que mais contribuem para o segundo fator são a percentagem de alojamentos com $50 \mathrm{~m}^{2}$ seguindo-se os alojamentos com uma ou duas divisões (Dimensão da Habitação). O terceiro fator está relacionado com a percentagem de alojamentos vazios e edifícios principalmente não residenciais, em oposição aos alojamentos familiares (Não Residencial). A percentagem de edifícios com 3 ou mais pisos e o uso de solo predominantemente urbano, em oposição à percentagem de edifícios com apenas 1 ou 2 pisos estão destacados no quarto fator (Área Urbana). No quinto fator o indicador com maior valor de loading é a percentagem de edifícios com placa (Material de Construção) e, finalmente no fator 6 (Área Agrícola), a percentagem de usos do solo com culturas temporárias é o único indicador com elevado valor de loading.

A Figura 2 representa a distribuição espacial dos scores/coordenadas por secção estatística, categorizados em quartis. Estas figuras revelam que os fatores 1 (Condições de Habitação), 2 (Dimensão da Habitação) e 5 (Material de Construção) não aparentam nenhum padrão na sua distribuição.
O fator 3 (Não Residencial) apresenta valores mais elevados nas secções centrais assim como nas secções próximas do rio. A maioria das secções do município de Lisboa apresenta valores de scores superiores a 0 (valor da média) no fator 4 (Área Urbana) e, as secções com maior área e mais periféricas apresentam os valores de scores mais elevados no fator 6 (Áreas Agrícolas).

Quadro I

Loadings e \% de variância explicada por fator.

\begin{tabular}{|c|c|c|c|}
\hline $\begin{array}{l}\text { Fator } \\
\text { (\% Variância } \\
\text { Explicada) }\end{array}$ & Indicador & Loadings & Designação \\
\hline \multirow{4}{*}{$(28,76 \%)$} & $\begin{array}{l}\% \text { alojamentos com } \\
\text { água }\end{array}$ & 0,953 & \multirow{4}{*}{$\begin{array}{l}\text { Condições da } \\
\text { Habitação }\end{array}$} \\
\hline & $\begin{array}{l}\% \text { alojamentos com } \\
\text { retrete }\end{array}$ & 0,941 & \\
\hline & $\begin{array}{l}\% \text { alojamentos com } \\
\text { esgoto }\end{array}$ & 0,937 & \\
\hline & $\begin{array}{l}\% \text { alojamentos com } \\
\text { banho }\end{array}$ & 0,731 & \\
\hline \multirow{4}{*}{ (14.49\%) } & $\begin{array}{l}\% \text { alojamentos com } \\
50 \mathrm{~m}^{2}\end{array}$ & 0,855 & \multirow{4}{*}{$\begin{array}{l}\text { Dimensão da } \\
\text { Habitação }\end{array}$} \\
\hline & $\begin{array}{l}\text { \% alojamento com } 1 \\
\text { ou } 2 \text { divisões }\end{array}$ & 0,696 & \\
\hline & $\begin{array}{l}\% \text { edifícios sem } \\
\text { placa }\end{array}$ & 0,668 & \\
\hline & $\begin{array}{l}\text { \% alojamento com } 3 \\
\text { ou } 4 \text { divisões }\end{array}$ & 0,625 & \\
\hline \multirow{3}{*}{$\begin{array}{l}3 \\
(10.24 \%)\end{array}$} & $\begin{array}{l}\% \text { alojamentos } \\
\text { vazios }\end{array}$ & 0,857 & \multirow{3}{*}{ Não Residencial } \\
\hline & $\begin{array}{l}\text { \% edifícios prin- } \\
\text { cipalmente não } \\
\text { residenciais }\end{array}$ & 0,669 & \\
\hline & $\begin{array}{l}\% \text { alojamentos } \\
\text { familiares }\end{array}$ & $-0,858$ & \\
\hline \multirow[b]{3}{*}{ (8.30\%) } & $\begin{array}{l}\text { \% edifícios com } 3 \\
\text { ou mais pisos }\end{array}$ & 0,838 & \multirow{3}{*}{ Área Urbana } \\
\hline & $\%$ urbano & 0,583 & \\
\hline & $\begin{array}{l}\% \text { edifícios com } 1 \\
\text { ou } 2 \text { pisos }\end{array}$ & $-0,838$ & \\
\hline \multirow[b]{2}{*}{$(6.76 \%)$} & $\begin{array}{l}\% \text { edifícios com } \\
\text { placa }\end{array}$ & 0,915 & \multirow{2}{*}{$\begin{array}{l}\text { Material de } \\
\text { Construção }\end{array}$} \\
\hline & $\begin{array}{l}\text { \% edifícios em } \\
\text { betão }\end{array}$ & $-0,723$ & \\
\hline (5.60\%) & $\begin{array}{l}\% \text { culturas tempo- } \\
\text { rárias }\end{array}$ & 0,964 & Área Agrícola \\
\hline
\end{tabular}



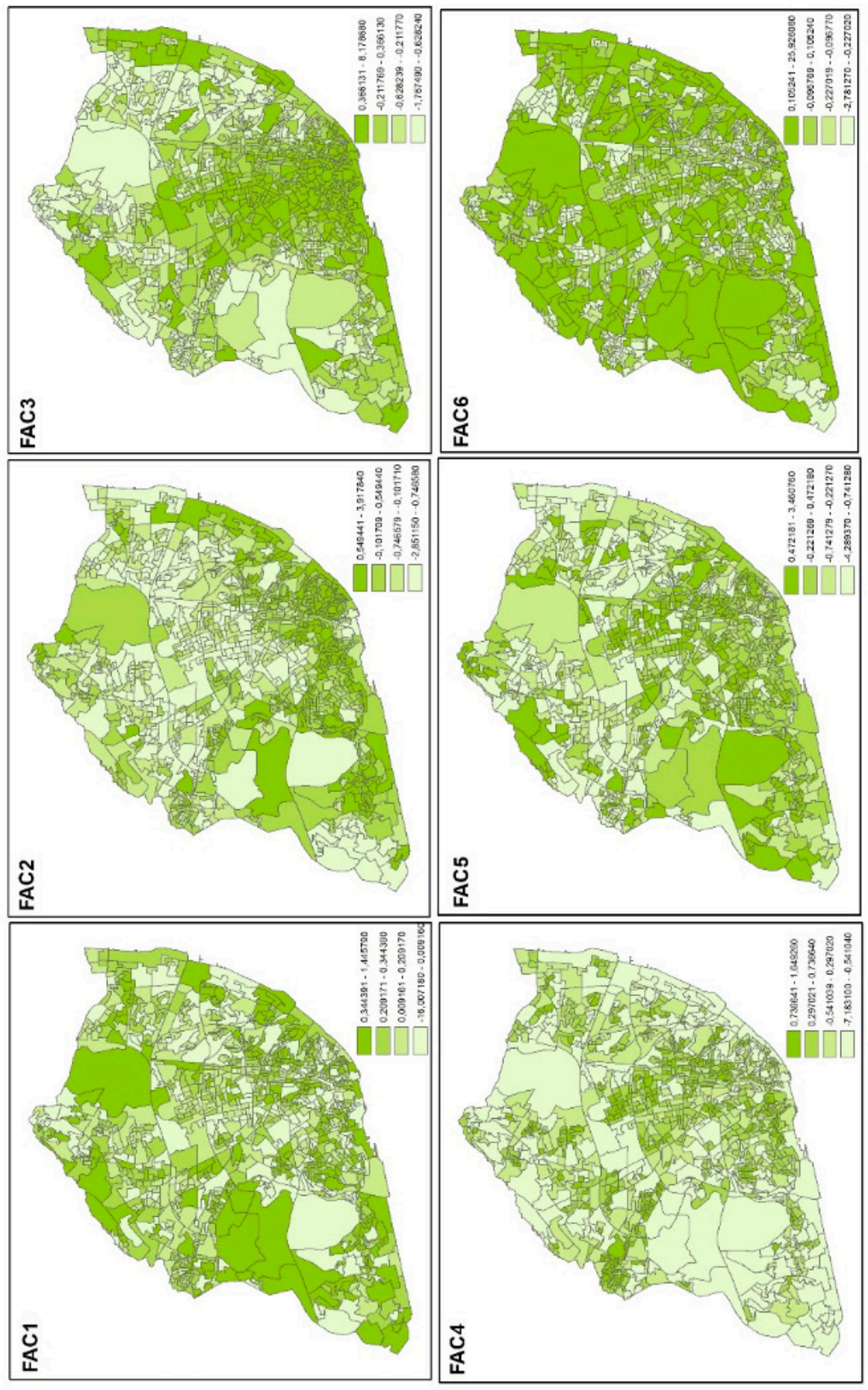

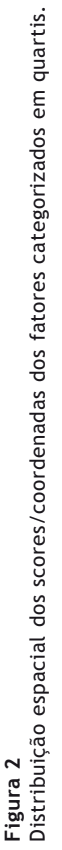

- Cada fator apresenta, em cada uma das secções em análise, um valor específico de "score". Assim, o "score" representa a expressão, em cada secção, de cada um dos fatores considerados, assumindo-se como uma faceta distintiva das áreas em estudo. 

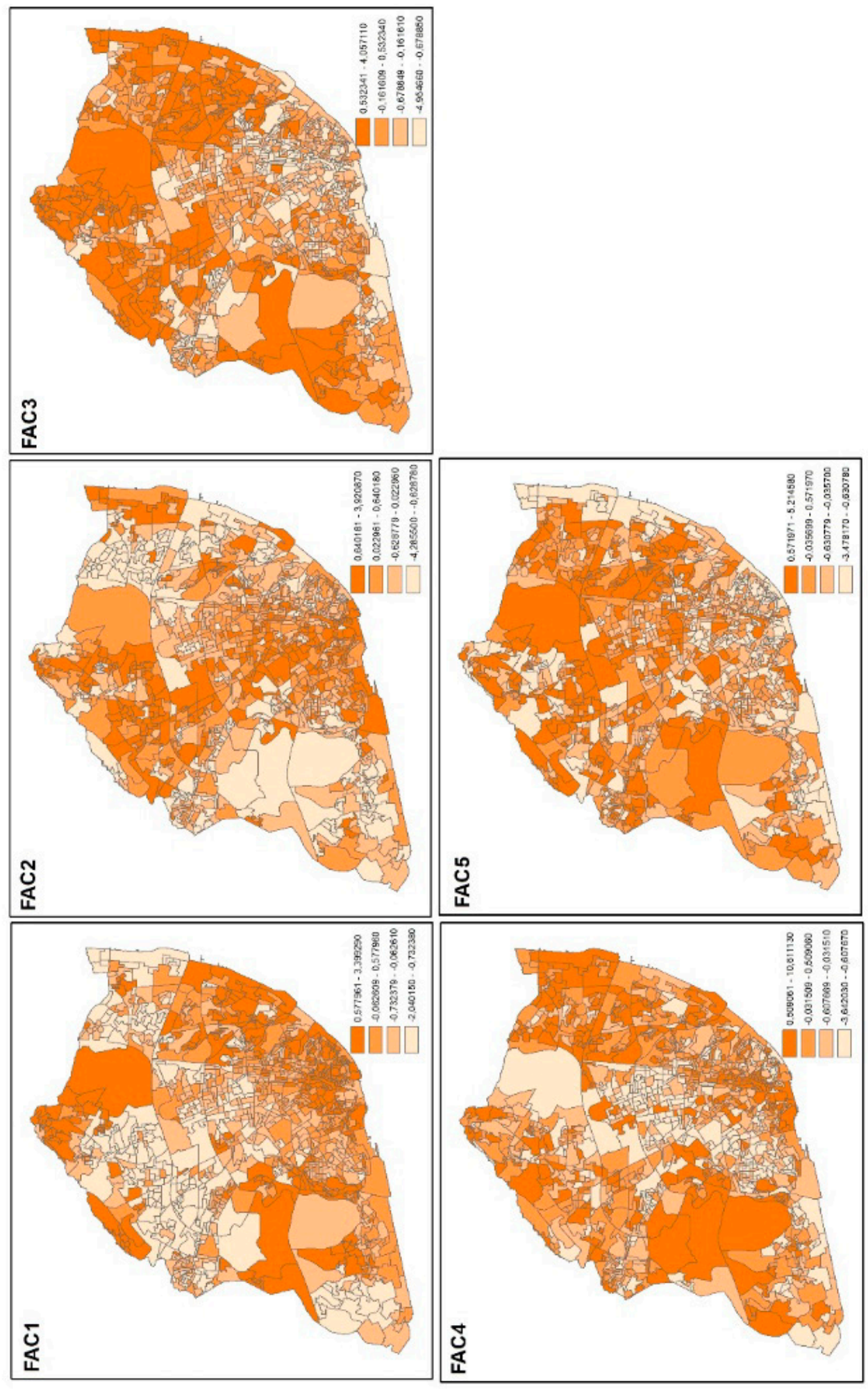

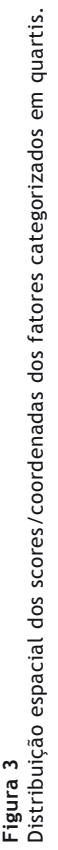




\section{Aspetos Sociais}

O Quadro II apresenta os loadings mais elevados por fator e a percentagem de variância explicada par a dimensão AS. Neste caso, os cinco fatores resultantes explicam quase $82 \%$ da variância deste grupo de indicadores.

Os indicadores no fator 1 estão associados com a situação laboral, o nível de escolaridade e o tipo de propriedade do alojamento de residência (Baixo Nível Socioeconómico). O segundo fator destaca indivíduos empregados no setor terciário, em idade ativa em oposição a residentes com mais de 65 anos e reformados (Empregado Terciário). No fator 3 a percentagem de famílias com 3 ou 4 pessoas e com crianças com menos de 15 anos de idade têm os loadings positivos mais elevados surgindo as famílias de menor dimensão com valor negativo elevado (Famílias com Menores de 15). O quarto fator relaciona-se com a percentagem de homens e mulheres residentes (Género dos Residentes) e, finalmente a percentagem de famílias com crianças acima de 15 anos de idade à procura do primeiro emprego têm valores de loadings mais elevados no fator 5 (Famílias com Maiores de 15).

A distribuição espacial do fator 1 (Baixo Nível Socioeconómico) mostra que as secções com scores mais elevados se localizam no centro de Lisboa e perto do rio. 0 fator 2 (Emprego no Terciário) e 4 (Género dos Residentes) não apresentam um padrão de distribuição dos valores de scores por secção. As secções com os valores mais elevados no fator 3 (Famílias com Menores de 15), localizam-se nas áreas periféricas assim como na área mais a nordeste do município. As secções com valores de scores mais elevado no fator 5 (Famílias com Maiores de 15) parecem estar concentradas nas áreas periféricas e mais a norte do município (Figura 3).

Classificação Hierárquica Ascendente (análise de clusters)

A classificação efetuada sugeriu a formação de quatro clusters distintos. Figura 4 e o Quadro III sintetizam a informação por cluster permitindo a sua melhor compreensão. No gráfico da Figura 4, que apresenta as médias dos fatores por cluster, pode comprovar-se que cada cluster representa uma conjugação diferente de valores dos fatores que o constitui.

Resumidamente, o cluster 1 integra secções que se assemelham entre si no que respeita à dimensão da habitação (alojamento de pequena dimensão),
Quadro II

Loadings e \% de Variância explicada por Fator.

\begin{tabular}{|c|c|c|c|}
\hline $\begin{array}{l}\text { Fator } \\
\text { (\% Variância } \\
\text { Explicada) }\end{array}$ & Indicador & $\begin{array}{l}\text { Loa- } \\
\text { dings }\end{array}$ & $\begin{array}{l}\text { Designa- } \\
\text { ção }\end{array}$ \\
\hline \multirow{9}{*}{ (35.68\%) } & $\begin{array}{l}\% \text { alojamentos ocupados por } \\
\text { arrendatários }\end{array}$ & 0,889 & \multirow{9}{*}{$\begin{array}{l}\text { Baixo } \\
\text { Nível } \\
\text { Socioe- } \\
\text { conó- } \\
\text { mico }\end{array}$} \\
\hline & $\begin{array}{l}\% \text { residentes à procura de } \\
\text { emprego }\end{array}$ & 0,833 & \\
\hline & $\begin{array}{l}\text { \% famílias clássicas com } \\
\text { desemprego }\end{array}$ & 0,782 & \\
\hline & $\begin{array}{l}\text { \% residentes que não sabem } \\
\text { ler nem escrever }\end{array}$ & 0,733 & \\
\hline & $\begin{array}{l}\% \text { residentes com o } 2^{\circ} \text { ciclo do } \\
\text { ensino básico }\end{array}$ & 0,725 & \\
\hline & $\begin{array}{l}\% \text { residentes com o } 1^{\circ} \text { ciclo do } \\
\text { ensino básico }\end{array}$ & 0,714 & \\
\hline & $\begin{array}{l}\% \text { residentes com o ensino } \\
\text { superior }\end{array}$ & $-0,765$ & \\
\hline & $\begin{array}{l}\text { \% famílias clássicas sem } \\
\text { desemprego }\end{array}$ & $-0,782$ & \\
\hline & $\begin{array}{l}\text { \% alojamentos ocupados pelos } \\
\text { proprietários }\end{array}$ & $-0,867$ & \\
\hline \multirow{6}{*}{ (26.39\%) } & $\%$ residentes empregados & 0,779 & \multirow{6}{*}{$\begin{array}{l}\text { Empre- } \\
\text { gado } \\
\text { Terciá- } \\
\text { rio }\end{array}$} \\
\hline & $\begin{array}{l}\% \text { residentes empregados no } \\
\text { setor terciário }\end{array}$ & 0,765 & \\
\hline & $\begin{array}{l}\% \text { residentes entre os } 15 \text { e os } \\
64 \text { anos de idade }\end{array}$ & 0,759 & \\
\hline & $\begin{array}{l}\% \text { residentes com o } 3^{\circ} \text { ciclo do } \\
\text { ensino básico }\end{array}$ & $-0,456$ & \\
\hline & $\begin{array}{l}\% \text { residentes com } 65 \text { anos de } \\
\text { idade }\end{array}$ & $-0,723$ & \\
\hline & $\%$ residentes reformados & $-0,769$ & \\
\hline \multirow{5}{*}{ (8.79\%) } & $\begin{array}{l}\% \text { famílias clássicas com } 3 \text { ou } \\
4 \text { pessoas }\end{array}$ & 0,805 & \multirow{5}{*}{$\begin{array}{l}\text { Famílias } \\
\text { com } \\
\text { Menores } \\
\text { de } 15\end{array}$} \\
\hline & $\begin{array}{l}\text { \% famílias nucleares com } \\
\text { crianças com - de } 15 \text { anos }\end{array}$ & 0,72 & \\
\hline & $\begin{array}{l}\text { \% residentes empregados no } \\
\text { setor secundário }\end{array}$ & 0,444 & \\
\hline & $\begin{array}{l}\text { \% residentes com o ensino } \\
\text { secundário }\end{array}$ & $-0,677$ & \\
\hline & $\begin{array}{l}\% \text { famílias clássicas com } 1 \text { ou } \\
2 \text { pessoas }\end{array}$ & $-0,829$ & \\
\hline \multirow[b]{2}{*}{$(5.59 \%)$} & $\%$ residentes masculinos & 0,904 & \multirow{2}{*}{$\begin{array}{l}\text { Género } \\
\text { dos } \\
\text { Residen- } \\
\text { tes }\end{array}$} \\
\hline & $\%$ residentes femininos & $-0,904$ & \\
\hline 5 & $\begin{array}{l}\% \text { residentes à procura do } 1^{\circ} \\
\text { emprego }\end{array}$ & 0,539 & \multirow{2}{*}{$\begin{array}{l}\text { Famílias } \\
\text { com } \\
\text { Maiores } \\
\text { de } 15\end{array}$} \\
\hline$(5.09 \%)$ & $\begin{array}{l}\text { \% famílias nucleares com } \\
\text { crianças com + de } 15 \text { anos }\end{array}$ & 0,807 & \\
\hline
\end{tabular}




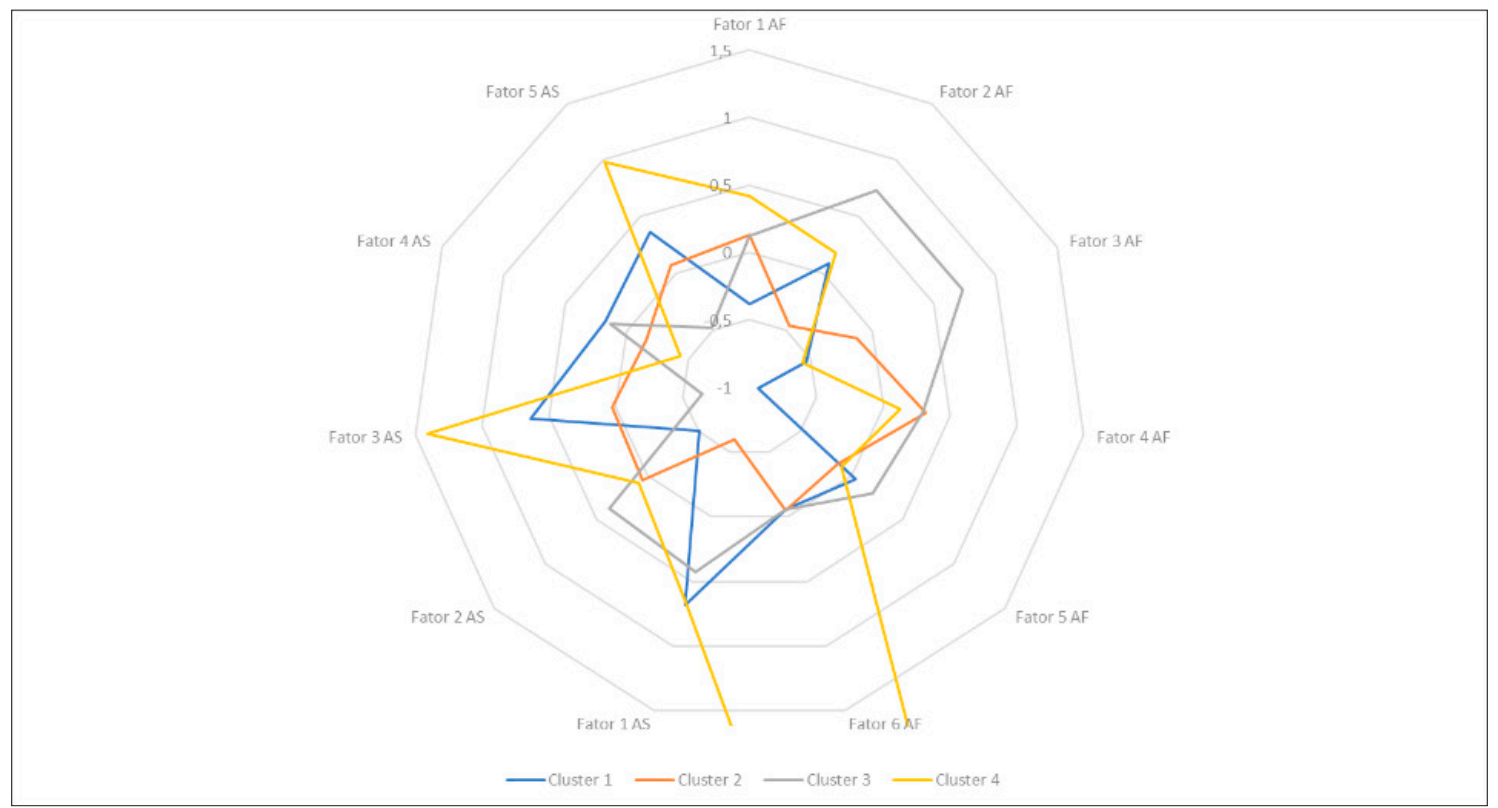

Figura 4

Média dos scores dos fatores por cluster.

Nota: 0 valor médio do fator 6 AF (Área Agrícola) é demasiado elevado para ser representado neste gráfico $(13,79)$.

com um baixo nível socioeconómico e com famílias com menores e maiores de 15 anos. O cluster 2 é constituído por secções predominantemente urbanas com boas condições de habitabilidade, famílias com maiores de 15 e empregados no terciário. No cluster 3 encontram-se secções caracterizadas pela pequena dimensão da habitação e edifícios principalmente não residenciais. Neste cluster as secções apresentam conjuntamente um baixo nível socioeconómico assim como empregados no terciário.

O cluster 4 está essencialmente relacionado com área agrícola, no que diz respeito ao uso do solo (Quadro III).

É importante salientar que esta leitura dos clusters se baseia nos fatores que apresentam maior média de score em cada cluster. Todavia, e como se pode verificar na figura 4 , cada cluster é também constituído por todos os outros fatores, englobando pois a totalidade dos aspetos considerados, tanto físicos como sociais. Assim, secções classificadas como pertencentes a um determinado cluster não são caracterizadas exclusivamente pelo(s) fator(es) aí preponderante(s), mas também pelos restantes fatores e variáveis. Consequentemente, não é possível nem correto afirmar que, por exemplo, as secções classificadas como cluster 4 sejam áreas exclusivamente agrícolas.

O cluster 1 (Áreas de Vulnerabilidade Socioeconómica) engloba $24,79 \%$ da população residente na área de estudo, o que sublinha a precariedade
Quadro III

Descrição Sintética dos Fatores por Cluster.

\begin{tabular}{|c|c|c|c|}
\hline Clusters & $\begin{array}{l}\text { Fator com } \\
\text { Média de } \\
\text { Scores } \\
\text { mais Elevada }\end{array}$ & Descrição & Designação \\
\hline 1 & $\begin{array}{l}\text { Fator } 2 \mathrm{AF} \\
\text { Fator } 1 \mathrm{AS} \\
\text { Fator } 3 \mathrm{AS} \\
\text { Fator } 5 \text { AS }\end{array}$ & $\begin{array}{l}\begin{array}{l}\text { Dimensão da Habi- } \\
\text { tação }\end{array} \\
\text { Baixo Nível Socioe- } \\
\text { conómico } \\
\text { Famílias com Meno- } \\
\text { res de } 15 \\
\text { Famílias com Maio- } \\
\text { res de } 15\end{array}$ & $\begin{array}{l}\text { Áreas de } \\
\text { Vulnerabilidade } \\
\text { Socioeconó- } \\
\text { mica }\end{array}$ \\
\hline 2 & $\begin{array}{l}\text { Fator } 4 \mathrm{AF} \\
\text { Fator } 1 \mathrm{AF} \\
\text { Fator } 5 \mathrm{AS} \\
\text { Fator } 2 \mathrm{AS}\end{array}$ & $\begin{array}{l}\text { Área Urbana } \\
\text { Condições da Habi- } \\
\text { tação } \\
\text { Famílias com Maio- } \\
\text { res de } 15 \\
\text { Empregado Terciário }\end{array}$ & $\begin{array}{l}\text { Área de Maior } \\
\text { Urbanidade }\end{array}$ \\
\hline 3 & $\begin{array}{l}\text { Fator } 2 \mathrm{AF} \\
\text { Fator } 3 \mathrm{AF} \\
\text { Fator } 1 \mathrm{AS} \\
\text { Fator } 2 \mathrm{AS}\end{array}$ & $\begin{array}{l}\text { Dimensão da Habi- } \\
\text { tação } \\
\text { Não Residencial } \\
\text { Baixo Nível Socioe- } \\
\text { conómico } \\
\text { Empregado Terciário }\end{array}$ & $\begin{array}{l}\text { Áreas Urbanas } \\
\text { Essencialmente } \\
\text { Não Residen- } \\
\text { ciais }\end{array}$ \\
\hline 4 & Fator $6 \mathrm{AF}$ & Área Agrícola & $\begin{array}{l}\text { Área Essencial- } \\
\text { mente Agrícola }\end{array}$ \\
\hline
\end{tabular}




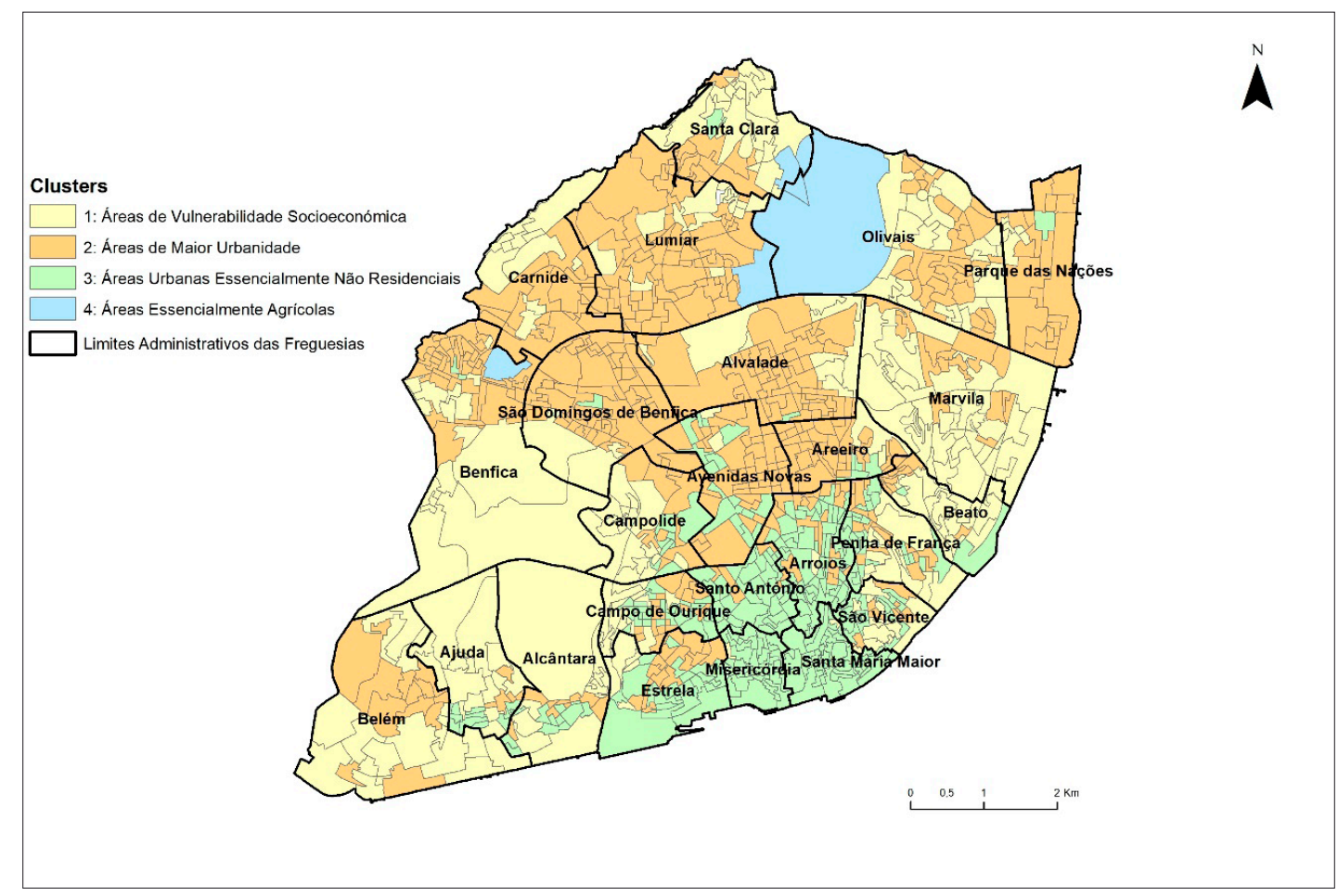

Figura 5

Distribuição Espacial dos Clusters.

Fonte: Instituto Nacional de Estatística (http://mapas.ine.pt/download/index2011.phtml).

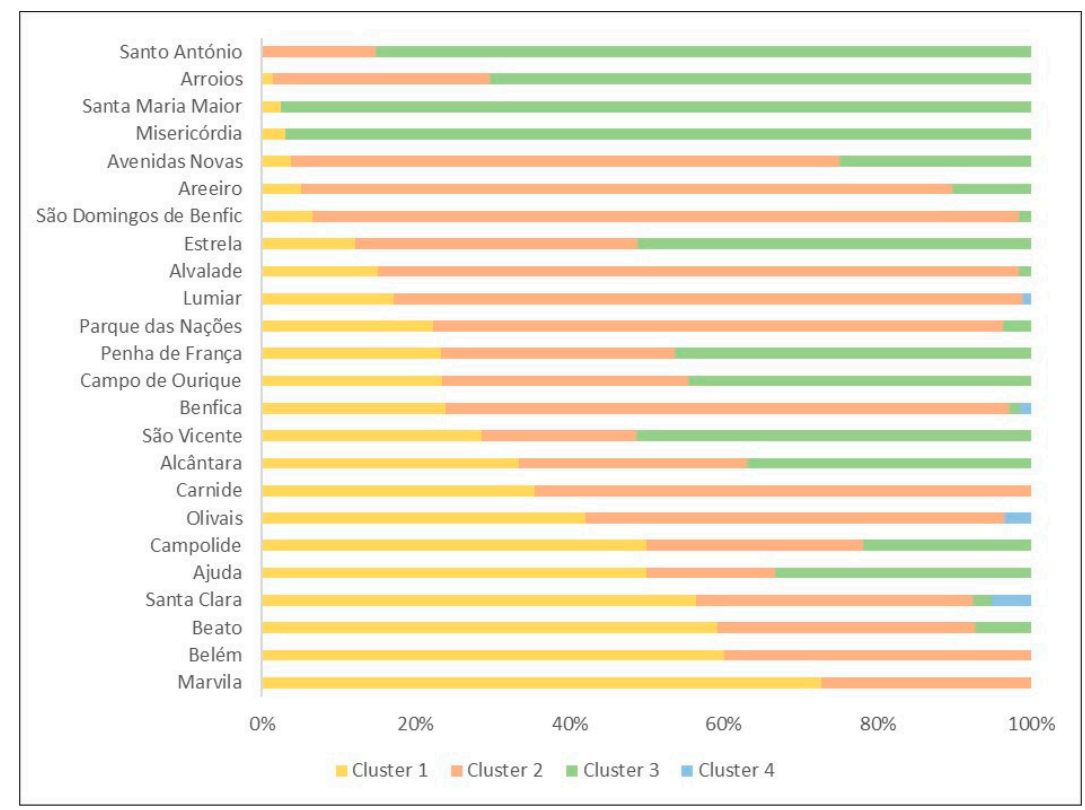

Figura 6

Percentagem de secções estatísticas por cluster e freguesia. 
em que quase um quarto dos indivíduos residentes deste município se encontra.

Por outro lado, cerca de $48 \%$ das secções estatísticas, onde reside quase metade da populaçãodo concelho de Lisboa, são Áreas de Maior Urbanidade (cluster 2) - com boas condições de habitação e empregos no terciário. No cluster 3 (Áreas Urbanas Essencialmente Não Residenciais) residem pouco mais de $21 \%$ da população de todo o concelho, em cerca de $27 \%$ das suas secções estatísticas. E no cluster 4 (Áreas Essencialmente Agrícolas) que engloba apenas 4 secções vivem 2226 (0,38\%) indivíduos (Quadro IV).

Quadro IV

Secções e população por cluster.

\begin{tabular}{|l|l|l|l|l|}
\hline \multirow{2}{*}{ Cluster } & \multicolumn{2}{|l|}{ Secções } & \multicolumn{2}{l|}{ População } \\
\cline { 2 - 5 } & N & $\%$ & N & $\%$ \\
\hline 1 & 261 & 24,79 & 153528 & 28,03 \\
\hline 2 & 505 & 47,96 & 271641 & 49,59 \\
\hline 3 & 283 & 26,88 & 120338 & 21,97 \\
\hline 4 & 4 & 0,38 & 2226 & 0,41 \\
\hline
\end{tabular}

A Figura 5 revela que aparentemente, a distribuição espacial dos clusters parece fazer-se de acordo com um padrão. O valor do I de Moran confirma que a distribuição dos clusters está espacialmente autocorrelacionada e de forma significativa pois o I de Moran é igual a 0,49 com um z-score=28,37 e um $p=0,000$.

O mapa apresentado na Figura 5 sobrepõe os limites administrativos de cada freguesia do Município de Lisboa à distribuição dos clusters por secção estatística. Neste mapa verifica-se que existe bastante homogeneidade interna nas freguesias no que diz respeito aos clusters das secções que as compõem. Por exemplo, as freguesias de Misericórdia e Santa Maria Maior são quase exclusivamente Áreas Urbanas Essencialmente Não Residenciais, ou seja, são freguesias onde predominam os serviços e o comércio.

Analisando a percentagem de secções estatísticas por cluster e freguesia verificamos que (Figura 6):

- Marvila, Belém e Beato são as freguesias com maior percentagem de secções classificados como Áreas de Vulnerabilidade Socioeconómica (cluster 1)

- O cluster 2 (Áreas de Maior Urbanidade) encontra-se em maior percentagem nas freguesias de São Domingos de Benfica, Areeiro e Alvalade.

- Apenas 6 freguesias não têm secções classificadas como Áreas Urbanas Essencialmente Não Residenciais (cluster 3)
- Apenas 4 freguesias têm secções classificadas como Áreas Essencialmente Agrícolas (cluster 4)

Os resultados obtidos através desta metodologia vão de encontro à realidade do município de Lisboa a vários níveis. Por exemplo, foram classificadas como Áreas Urbanas Essencialmente Não Residências as secções que se encontram nas freguesias centrais e do centro histórico de Lisboa onde, apesar de ter havido um aumento da população residente entre 2001 e 2011, continua a considerar-se como prioritário o aumento dessa população nesta área, nomeadamente no PEDULx (Plano Estratégico de Desenvolvimento Urbano do Município de Lisboa, 2016). O centro histórico de Lisboa situa-se essencialmente nas freguesias da Estrela, Misericórdia e Santa Maria Maior. Ao longo do tempo, esta área ora foi povoada por elites da sociedade (nobreza antes do terratomo de 1755, por exemplo), ora por uma população empobrecida (proletariado na primeira metade do séc. XX). Hoje em dia o centro histórico parece estar a ser palco dum processo de gentrificação (enobrecimento), sendo simultaneamente alvo de políticas municipais que procuram impedir o afastamento da população mais desfavorecida aí residente (Galhardo, 2014).

Outro exemplo que demonstra a adequação dos clusters criados e a realidade do território em estudo é o fato da maioria das secções das freguesias de Marvila e Santa Clara serem classificadas como cluster 1 (Áreas de Maior Vulnerabilidade Socioeconómica). Ora segundo o PEDULx estes são também os locais onde se encontram as maiores percentagens de indivíduos residentes beneficiários do Rendimento Social de Inserção, sendo nestas freguesias que se localizam os maiores números de Zonas de Intervenção Prioritária ${ }^{8}$, previstas pela Câmara Municipal de Lisboa (Plano Estratégico de Desenvolvimento Urbano do Município de Lisboa, 2016).

\section{Vantagens e Limitações}

A principal característica da classificação territorial criada é não partir de preconceitos sobre a área de estudo, i.e., não há interferência ou escolha prévia da informação analisada inicialmente, nem da informação incluída no resultado final. Esta metodologia utiliza informação disponível para todo o país o que permite a replicação destes procedimentos analíticos noutros municípios, distritos e regiões.

\footnotetext{
Zonas de Intervenção Prioritária: instrumento de política pública municipal que visa dinamizar parcerias e pequenas intervenções locais de melhoria dos "habitats" abrangidos, através do apoio a projetos locais que contribuam para o reforço da coesão socio-territorial no município.
} 
Através do mapeamento dos clusters resultantes é possível identificar padrões de distribuição de cada cluster, calcular a sua autocorrelação espacial e identificar áreas com maior necessidade de intervenção ao nível de políticas estratégicas de desenvolvimento territorial, por exemplo. É também possível cruzar informação de diferente natureza com os clusters resultantes desta metodologia de análise do território, nomeadamente informação epidemiológica ou de saúde pública permitindo aferir a associação entre o contexto geográfico e a saúde das populações.

No entanto, os clusters resultantes desta metodologia serão diferentes consoante a área em estudo o que poderá ser visto como uma limitação pois desta forma não se poderão comparar diretamente os resultados de diferentes áreas.

\section{Conclusões}

A categorização do território é uma tarefa complexa devido essencialmente à multidimensionalidade do conceito "território" e ao elevado número de indicadores de base territorial disponível. Contudo, é essencial conhecer aprofundadamente o território, perceber as suas diferenças e interpretá-las. Só assim se poderá intervir no sentido da atenuação dessas diferenças, nomeadamente através dum planeamento estratégico e direcionado.

A ACP é a análise estatística mais adequada no que se refere à redução do número de indicadores necessários para descrever as unidades territoriais, sem prejuízo de perda de informação relevante. Contudo, a representação espacial da distribuição dos loadings dos fatores por secções é de difícil leitura e interpretação.

A aplicação da $\mathrm{CAH}$ aos fatores de AF e AS em conjunto facilita a interpretação da distribuição destas características por cluster e por secção, após mapeados.

O I de Moran comprova a aparente autocorrelação espacial do mapeamento da distribuição dos clusters por secções. As secções com AF e AS semelhantes são efetivamente mais próximas geograficamente agrupando-se espacialmente de forma significativa.

O agrupamento das secções por clusters é relativamente uniforme por freguesia existindo inclusivamente freguesias cujas secções pertencem quase exclusivamente a um só cluster.

A metodologia de análise fatorial, seguida de análise hierárquica e respetivo mapeamento e teste de autocorrelação espacial através do I de Moran provou ser útil na análise das secções estatísticas do Município de Lisboa. A agregação de secções não se deve ao acaso e a interpretação da informação de cada cluster parece ser teoricamente válida. No entanto, esta metodologia necessita de replicação, noutros territórios e noutras escalas, no sentido de comprovar a sua aplicabilidade.

\section{Bibliografia}

Albagli, S. (2004). Território e Territorialidade. In R. D. Editora (Ed.), Territórios em Movimento: Cultura e Identidade como Estratégia de Inserção Competitiva (pp. 23-70).

Allik, M., Brown, D., Dundas, R. \& Leyland, A. H. (2016). Developing a new small-area measure of deprivation using 2001 and 2011 census data from Scotland. Health Place, 39, 122 - 130. doi:10. 1016/j. healthplace.2016.03.006

Braga, R. M. (2007). O Espaço Geográfico: Um Esforço de Definição. GEOUSP - Espaço e Tempo, 22, 65-72.

Faria, R. M. d. \& Bortolozzi, A. (2009). Space, territory and health: contributions of Milton Santos for the theme of the geography of health in Brazil. Raega - O Espaço Geográfico em Análise, 17, 31-41.

Galhardo, J. (2014). As desigualdades fontes de dinâmicas urbanas no centro histórico de Lisboa. Cadernos Metrópole, 16(32), 513-536. doi:10.1590/22369996.2014-3210

Haesbaert, R. \& Limonad, E. (2007). 0 território em tempos de globalização. etc, espaço, tempo e crítica. Revista Eletrônica de Ciências Sociais Aplicadas e outras coisas, 1 (2 (4)), 39-52.

Ianoș, I., Petrișor, A.-I., Zamfir, D., Cercleux, A.-L., Stoica, I. -V. \& Tălângă, C. (2013). Search of a relevant index measuring territorial disparities in a transition country. Romania as a case study. Die Erde. Journal of the Geographical Society of Berlin, 144(1), 69-81. doi: 10.12854/erde-144-5

Knighton, A. J., Savitz, L., Belnap, T., Stephenson, B. \& VanDerslice, J. (2016). Introduction of an Area Deprivation Index Measuring Patient Socioeconomic Status in an Integrated Health System: Implications for Population Health. EGEMS (Wash DC), 4(3), 1238. doi:10.13063/2327-9214.1238

Langlois, A. \& Kitchen, P. (2001). Identifying and Measuring Dimensions of Urban Deprivation in Montreal: An Analysis of the 1996 Census Data. Urban Studies, 38(1), 119-139. doi:10.1080/00420980020014848 
Lian, M., Struthers, J. \& Liu, Y. (2016). Statistical Assessment of Neighborhood Socioeconomic Deprivation Environment in Spatial Epidemiologic Studies. Open J Stat, 6(3), 436-442. doi:10.4236/ojs.2016.63039

Martín, A. C. \& Barros, C. M. d. C. P. (2015). Designing a Living Conditions Index and Classification of the National Territory. Revista Cubana de Medicina General Integral, 31(3), 323-332.

Messer, L. C., Laraia, B. A., Kaufman, J. S., Eyster, J., Holzman, C., Culhane, J. \& O'Campo, P. (2006). The development of a standardized neighborhood deprivation index. J Urban Health, 83(6), 1041-1062. doi:10.1007/s11524-006-9094-x

Nogueira, H. (2006). Os lugares e a saúde: uma abordagem da Geografia às variações em saúde na Área Metropolitana de Lisboa. (Doutoramento), Universidade de Coimbra.
Norusis, M. J. (2005). IBM SPSS Statistics 19 Statistical Procedures Companion. In I. Corp. (Ed.), Straight Talk about Data Analysis and IBM SPSS Statistics (pp. 375404).

Plano Estratégico de Desenvolvimento Urbano do Município de Lisboa. (2016). Retrieved from

http://www.cmlisboa.pt/fileadmin/VIVER/Urbanismo/ urbanismo/PEDU/PEDU/PEDU_Relatorio_FINAL.pdf

Vyas, S. \& Kumaranayake, L. (2006). Constructing socioeconomic status indices: how to use principal components analysis. Health Policy Plan, 21(6), 459 468. doi:10.1093/heapol/czl029 